\title{
添加氧化铈对 AZ91D镁合金表面富镁涂层的保护作用
}

\author{
王雅萍赵旭辉卢向雨左 禹 ${ }^{*}$ \\ (北京化工大学材料科学与工程学院, 北京 100029)
}

\begin{abstract}
摘要: 通过 Machu测试、电化学交流阻抗(EIS)和扫描电子显微镜(SEM)等方法研究了添加氧化铈对 AZ91D 镁合金表面富镁涂层防护性能的影响. 氧化铈添加量较少 $(0.1 \%, w)$ 时, 对涂层耐蚀性无影响; 添加量过多 $(3 \%)$ 时, 涂层耐蚀性降低; 添加氧化铈颗粒为 $0.5 \%$ 时, 涂层的阻抗增大, 涂层电容降低, 对 AZ91D镁合金基体的保 护性能明显提高. 尽管添加氧化铈不改变富镁涂层对 AZ91D 镁合金的保护机制, 但可显著延长涂层的服役寿 命. 氧化铈能够降低纯镁颗粒的电化学反应活性, 使镁粉腐蚀速率降低, 阴极保护时间延长. 添加一定量氧化铈 后, 也有利于涂层屏蔽性能提高, 氧化铈能降低AZ91D 镁合金表面阳极腐蚀电流密度, 提高镁合金腐蚀电位, 从而有利于富镁涂层发挥对镁合金基体的阴极保护作用.
\end{abstract}

关键词：耐蚀性；AZ91D镁合金；富镁涂层；氧化铈；电化学交流阻抗 中图分类号: 0646

\section{Corrosion Protection of Ceria Particles in Mg-Rich Primer on AZ91D Magnesium Alloy}

\author{
WANG Ya-Ping \\ ZHAO Xu-Hui \\ LU Xiang-Yu \\ ZUO Yu* \\ (School of Materials Science and Engineering, Beijing University of Chemical Technology, Beijing 100029, P. R. China)
}

\begin{abstract}
The effect of ceria particles on the corrosion resistance of Mg-rich primer on AZ91D magnesium alloy was studied using the Machu test, electrochemical impedance spectroscopy (EIS), and scanning electron microscopy (SEM). The results show that addition of a small amount of cerium oxide $(0.1 \%$, mass fraction) had no effect on the corrosion resistance of the coating, and the addition of excessive particles $(3 \%)$ reduces the corrosion resistance of the coating. However, addition of $0.5 \%$ ceria particles to the Mg-rich primer can significantly improve the protection performance of the primer on AZ91D magnesium alloy. The coating resistance increases and coating capacitance decreases after the addition of ceria particles. Although the addition of ceria does not change the protection mechanisms of the magnesium-rich primer on AZ91D magnesium alloy, the electrochemical activity of the magnesium particles in the primer decreases and the service life of the Mg-rich primer is obviously prolonged. The ceria particles also result in an improved barrier effect. In addition, the presence of ceria particles on the AZ91D alloy surface can increase the corrosion potential and decrease the current density of the alloy, which is beneficial for cathode protection of the pure magnesium particles on the alloy substrate.
\end{abstract}

Key Words: Corrosion resistance; AZ91D magnesium alloy; Mg-rich primer; Ceria; Electrochemical impedance spectroscopy

Received: November 4, 2011; Revised: December 7, 2011; Published on Web: December 16, 2011.

"Corresponding author. Email: zuoy@mail.buct.edu.cn; Tel: +86-10-64423795.

The project was supported by the Foundation for Key Program of Ministry of Education, China (108129).

教育部科学技术重点项目(108129)资助

(C) Editorial office of Acta Physico-Chimica Sinica 


\section{1 引 言}

镁合金具有很高的比强度、比弹性模量, 以及 良好的导热、电磁屏蔽、阻尼减震和切削加工性能, 广泛应用于汽车、电子、航空等领域. 但是镁的腐蚀 电位很负, 化学性质活泼, 耐蚀性差. ${ }^{1,2}$ 有机涂层是 广泛应用的材料防腐蚀手段, ${ }^{3-5}$ 为进一步提高涂层 耐蚀性, 通常在涂层中添加活性颜料, 利用其牺牲 阳极的作用保护基底, 例如针对碳钢体系的富锌涂 层, ${ }^{6,7}$ 针对铝合金的富镁涂层. ${ }^{8-10}$ 研究表明, 纯镁相 对于镁合金电位较负, 在美合金表面镀一层纯镁, 作为阳极材料可以起到对镁合金基体保护的作 用. ${ }^{11}$ 我们 ${ }^{12}$ 在前期工作中利用纯镁粉作为活性颜料 添加到环氧树脂中, 镁颗粒作为阳极性组分对 AZ91D 镁合金基体具有阴极保护作用，同时也可以 增强涂层的屏蔽作用, 使涂层对镁合金的保护作用 显著加强. 但是由于镁粉活性很高, 当电解质溶液 渗透到涂层内部并快速与镁粉发生反应后, 容易使 涂层保护作用降低. 因此, 适当降低镁粉反应活性, 延长镁粉与电解质溶液反应时间, 进而延长镁粉对 基底的阴极保护作用时间, 有利于进一步提高富镁 涂层的保护性能. 研究表明, 氧化铈粒子能抑制金 属阳极反应. ${ }^{13,14}$ 本文将氧化铈颗粒添加到富镁涂层 后, 研究其对富美涂层耐蚀性的影响, 旨在找出一 种能抑制富镁涂层中镁粉反应活性的添加剂, 进一 步提高富镁涂层对镁合金的保护作用.

\section{2 实验方法}

\section{1 涂料制备与涂刷}

将AZ91D镁合金板材 (辽宁营口银河镁铝合金 有限公司)切割成 $50 \mathrm{~mm} \times 50 \mathrm{~mm} \times 2 \mathrm{~mm}$ 和 $150 \mathrm{~mm} \times$ $70 \mathrm{~mm} \times 2 \mathrm{~mm}$ 两种尺寸, 用 240 \#水砂纸去除氧化皮, 至合金表面光亮, 依次用去离子水、丙酮 $(99.5 \%)$ 擦 拭, 晾干备用. 实验所用镁粉 $(99.9 \%$, 北京纳辰科技 发展有限公司)平均粒径为 $25 \mu \mathrm{m}$, 氧化铈 $(99.99 \%$, 杭州万景新材料有限公司)粒径为 $0.3 \mu \mathrm{m}$.

涂料制备过程为: 称取一定量环氧树脂(H01-1, 金鱼涂料集团). 滴加少许硅烷偶联剂(KH560, 济南 市泽宇化工有限公司), 依次加入氧化铈颗粒(按镁 粉质量的 $0.1 \% 、 0.5 \% 、 3 \%$ 添加) 以及镁粉(质量分数 为干膜质量的 50\%), 摚拌并超声分散, 加入 $\mathrm{H} 01-1$ 配套固化剂, 环氧树脂与固化剂的质量比为 10:3. 配 制成的涂料静置 $1 \mathrm{~h}$.

采用常规涂刷方法在镁合金基体上制备涂层，
涂层晾干时间为一周. 用 TT 230 非磁性测厚仪测出 涂层厚度约为 $120 \mu \mathrm{m}$.

\subsection{Machu 测试}

Machu测试是检测涂层耐蚀性的加速腐蚀实 验, Machu 溶液由 $(50 \pm 1) \mathrm{g} \cdot \mathrm{L}^{-1}$ 氯化钠 $(99.5 \%)$ 和 $(5 \pm$ 1) $\mathrm{mL} \cdot \mathrm{L}^{-1}$ 过氧化氢 $(30 \%)$ 组成, 测试温度 $(37 \pm 1)^{\circ} \mathrm{C}$, 实验时间( $48.0 \pm 0.5) h$. 实验溶液的 $\mathrm{pH}$ 值约为 $7,24 \mathrm{~h}$ 后, 补充过氧化氢 $5 \mathrm{~mL}$.

镁合金试样表面涂层完全干燥后, 用刻刀在涂 层表面划两道夹角 $90^{\circ}$ 、长 $30 \mathrm{~mm}$ 的划痕, 划痕到达 基底. 将试样放入 Machu 溶液中测试, $48 \mathrm{~h}$ 后观察涂 层表面腐蚀形貌, 以判定涂层的耐蚀性能.

\section{3 交流阻抗与极化曲线测试}

采用 PARSTAT 2273(美国普林斯顿)电化学工 作站, 在开路电位下测试镁合金涂层试样在质量分 数为 $3 \%$ 的氯化钠溶液中的交流阻抗谱图, 测试频 率范围为 $100 \mathrm{kHz}-10 \mathrm{mHz}$, 交流正弦波信号幅值为 $10 \mathrm{mV}$. 电解池采用传统的三电极体系, 饱和甘录电 极 $(\mathrm{SCE})$ 为参比电极, 铂电极 $(\mathrm{Pt})$ 为辅助电极, 带有 涂层的 AZ91D 镁合金为工作电极, 测试面积约为 $10 \mathrm{~cm}^{2}$. 每组实验测试三次以验证结果重现性. 极化 曲线测试采用 CS300 电化学工作站(武汉科斯特), 参比电极为饱和甘录电极, 辅助电极为铂电极, 工 作电极为镁合金, 扫描速率为 $0.3 \mathrm{mV} \cdot \mathrm{s}^{-1}$. 实验均在 室温下进行.

\section{3 结果与讨论}

\section{1 不同含量氧化铈对富镁涂层耐蚀性的影响}

将氧化铈分别按镁粉质量的 $0.1 \% 、 0.5 \% 、 3 \%$ 添加到富镁涂层中, 通过 Machu测试考察涂层耐蚀 性变化. 图 1 为添加不同含量氧化铈的富镁涂层 Machu 测试 $7 \mathrm{~d}$, 剥掉涂层后暴露的基底腐蚀形貌. Machu测试后, 含有 $0.1 \% 、 3 \%$ 与不含有氧化铈的基 底黑色腐蚀产物较多, 含有 $0.5 \%$ 氧化铈的基底腐蚀 产物很少。

通过 Machu实验可以看出, 在富镁涂层中添加 一定含量的氧化铈颗粒使涂层对基体的保护能力 显著提高. 粒子添加量过少对涂层无明显影响, 添 加量过多导致涂层附着力降低, 进而耐蚀性降低. 氧化铈是无机粒子, 与环氧涂层存在相容性问题, 添加量过多会导致涂层附着力下降; 另外, 有文献 ${ }^{14}$ 指出, 涂层中添加颗粒过多, 会导致涂层孔隙率增 加, 降低涂层的屏蔽性能. 

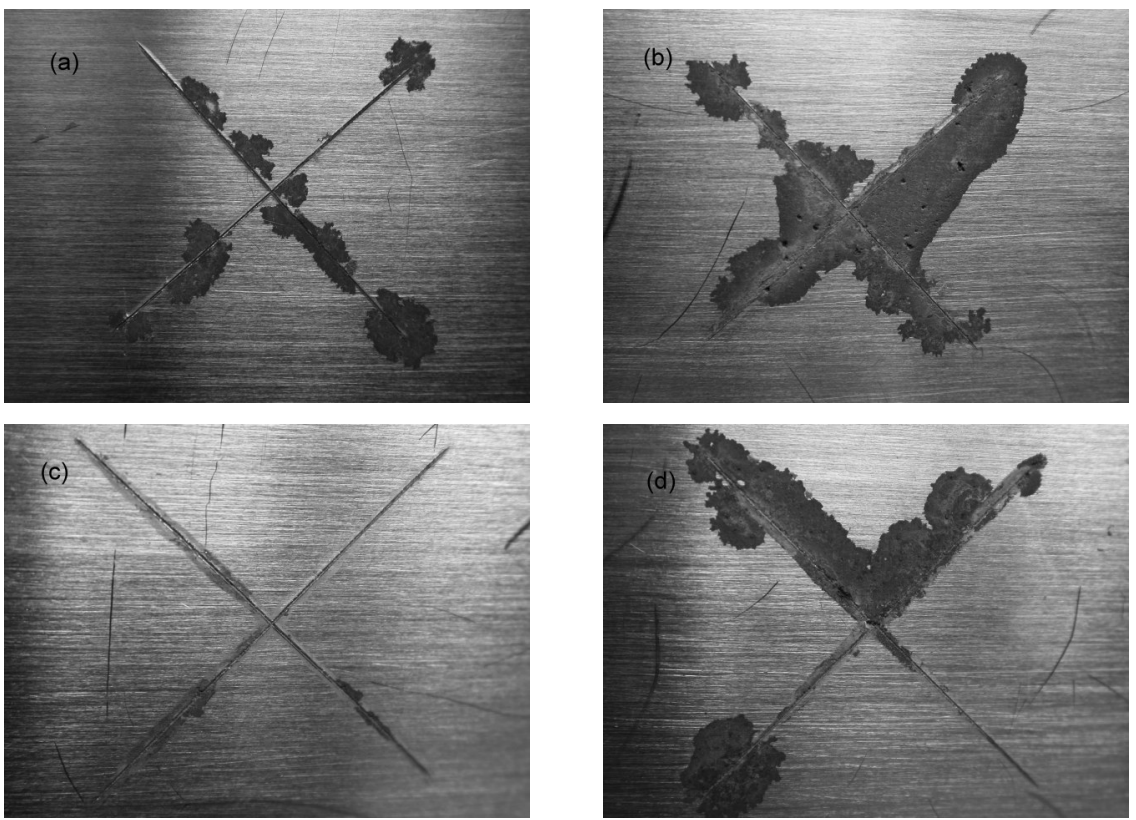

图 1 添加不同质量分数氧化铈的富镁涂层经 Machu测试剥掉涂层后基底腐蚀形貌

Fig.1 Surface morphologies of Machu tested Mg-rich primers with different mass fractions of ceria after removing primer $w_{\text {ceria }} \%$ : (a) 0 ; (b) 0.1 ; (c) 0.5 ; (d) 3

\section{2 交流阻抗测试与参数拟合}

交流阻抗测试能定量反映出涂层降解与失效 过程, 图 2 是不含氧化铈的富镁涂层浸泡不同时间 后在 3\%氯化钠溶液中的交流阻抗谱图.

浸泡初期 $(1 \mathrm{~h})$, Bode 图为近似斜率为 -1 的直 线, $0.01 \mathrm{~Hz}$ 处阻抗模值接近 $10^{11} \Omega \cdot \mathrm{cm}^{2}$, Nyquist 图 上高频段出现半径较大的容抗弧. 此时涂层相当于 一个阻抗值很大的隔绝层, 对基体有良好的阻挡保 护作用. ${ }^{15}$ 因此采用图 3(a)中的 Model A 等效电路进 行拟合, $Q_{\mathrm{c}}$ 为涂层电容, $R_{\mathrm{c}}$ 为涂层电阻, 拟合结果如 图 4 所示. 浸泡 $24 \mathrm{~h}$ 后, $0.01 \mathrm{~Hz}$ 处阻抗模值与初始 相比降低一个数量级, 可能由于电解质溶液通过涂 层孔隙与缺陷渗透到涂层内部, 并与镁粉发生反应

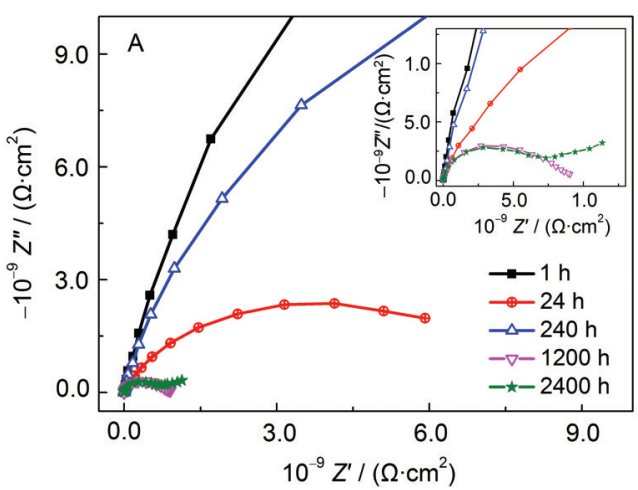

所致. 此时采用图 3(b)中的 Model B 等效电路进行 拟合, 其中 $R_{\mathrm{ct}}$ 为镁粉表面的界面反应电阻, $Q_{\mathrm{dl}}$ 为镁 粉表面双电层电容, $Q_{\text {diff }}$ 表示扩散层电容, $R_{\text {diff }}$ 表示扩 散层电阻, $Z_{\mathrm{diff}}$ 表示两者并联组成一个扩散阻抗. 与镁 粉颗粒的腐蚀产物堵塞涂层中溶液渗透通道引起 的有限层扩散有关, ${ }^{9,12}$ 拟合结果如图 4 所示. 浸泡 $1200 \mathrm{~h}$ 后, Nyquist 图上低频端开始出现另一个时间 常数, Bode 图上低频端出现较宽的平阶, 此时采用 等效电路 Model B 已不能得到良好的拟合结果, 而 等效电路 Model C 可很好地拟合阻抗实验数据, 其 中 $Q_{\mathrm{sf}}$ 和 $R_{\mathrm{sf}}$ 分别表示基体表面腐蚀的双电层电容和 界面反应电阻, 拟合结果如图 4 所示. 此时电解质溶 液已经渗透到涂层/基底界面, 并与基底发生反应,

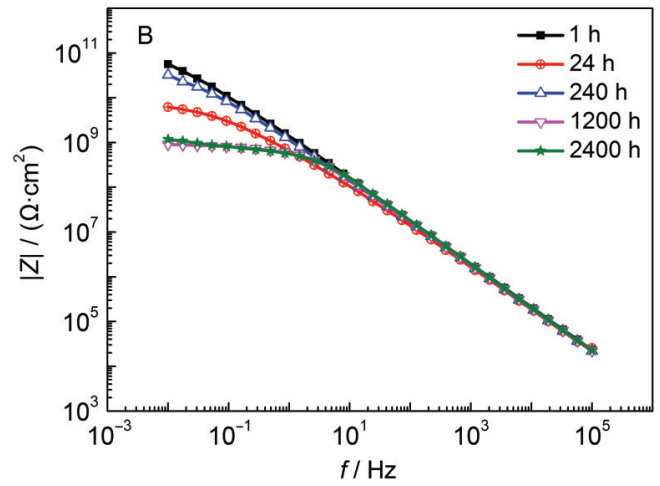

图 2 不含氧化铈的富镁涂层在 $3 \%$ 氯化钠溶液中浸泡不同时间的交流阻抗谱图

Fig.2 EIS spectra of Mg-rich primer without ceria after different immersion time in $3 \% \mathrm{NaCl}$ solution (A) Nyquist plots; (B) Bode plots 

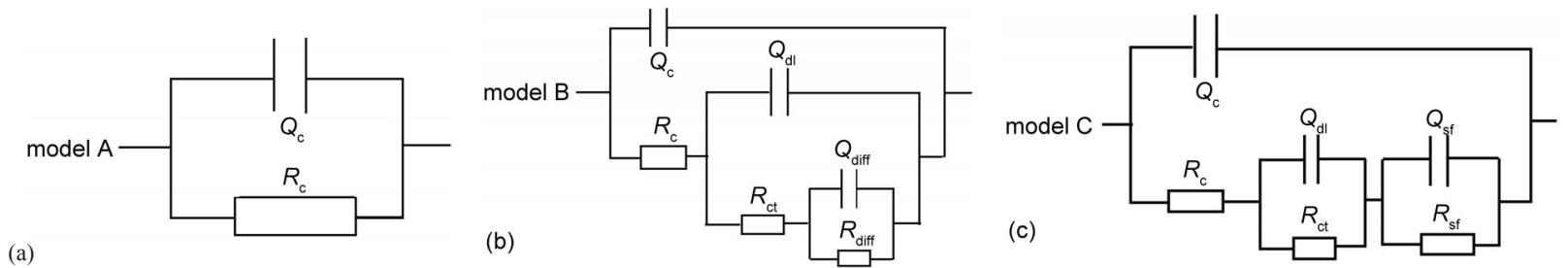

图 3 富镁涂层试样在 $3 \%$ 氯化钠溶液中浸泡不同时间的交流阻抗图谱拟合等效电路

Fig.3 Equivalent electrical circuits for EIS spectra of Mg-rich primer after different immersion time in 3\% NaCl solution $Q_{\mathrm{c}}$ : coating capacitance; $R_{\mathrm{c}}$ : coating resistance; $Q_{\mathrm{dl}}$ : double-layer capacitance; $R_{\mathrm{ct}}:$ charge-transfer resistance; $Q_{\mathrm{s}}$ : double-layer capacitance at substrate/ coating interface; $R_{\mathrm{sf}}$ : charge-transfer resistance of the substrate; $Q_{\text {diff: }}$ diffused layer capacitance, $R_{\text {diff: }}$ diffused layer resistance
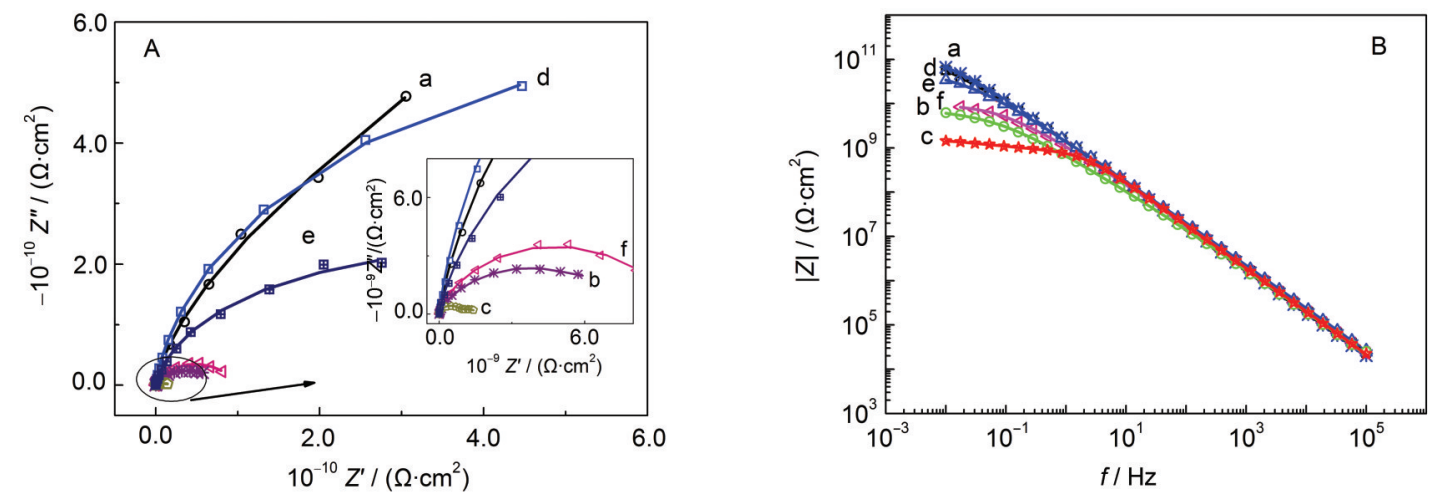

图 4 两种富镁涂层在 $3 \%$ 氯化钠溶液中浸泡不同时间的交流阻抗图谱拟合结果

Fig.4 Fitting of EIS spectra for two Mg-rich primers after different immersion time in $3 \% \mathrm{NaCl}$ solution

(A) Nyquist plots, (B) Bode plots; dot: experimental data, line: fitting results; (a) $50 \% \mathrm{Mg}, 1 \mathrm{~h}$; (b) $50 \% \mathrm{Mg}$, 24 h; (c) $50 \% \mathrm{Mg}, 1200 \mathrm{~h}$; (d) $50 \%$ $\mathrm{Mg}+0.5 \%$ ceria, $1 \mathrm{~h}$; (e) $50 \% \mathrm{Mg}+0.5 \%$ ceria, $48 \mathrm{~h}$; (f) $50 \% \mathrm{Mg}+0.5 \%$ ceria, $2400 \mathrm{~h}$

涂层开始失去保护作用. 从图 5 涂层截面扫描形貌 看到, 浸泡 $2400 \mathrm{~h}$ 后, 涂层内部镁粉周边产生疏松 的腐蚀产物, 基底上也出现局部蚀坑.

在富镁涂层中添加 $0.5 \%$ 的氧化铈后, 交流阻抗 谱图如图 6 所示, 涂层阻抗的变化趋势与图 2 基本 一致. 但是该涂层浸泡 $2400 \mathrm{~h}$ 后, Nyquist 图低频端 仍未出现另一个时间常数, Bode图上低频端仍未出 现较宽的平阶, 说明此时涂层仍具有良好的保护作 用. 从图 7涂层截面扫描形貌看到, 浸泡 $2400 \mathrm{~h}$ 后的 基底保持完好, 没有出现蚀坑.

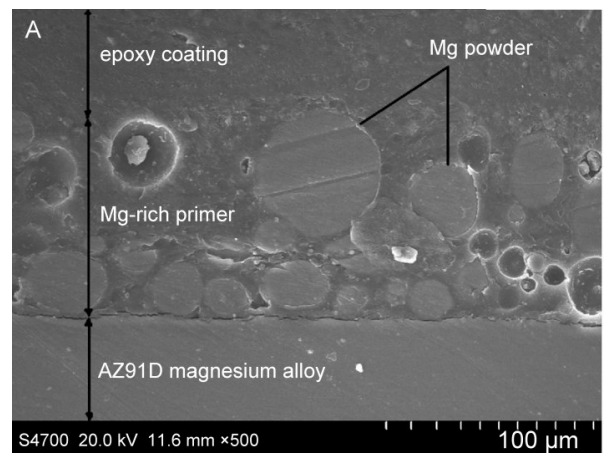

图 5 不含氧化铈的富镁涂层在 $3 \%$ 氯化钠中浸泡前后的涂层断面扫描形貌

Fig.5 Cross-section morphologies of the Mg-rich primer without ceria before and after immersion in $3 \% \mathrm{NaCl}$ solution

(A) before immersion; (B) after $2400 \mathrm{~h}$ immersion

采用图 3 中的等效电路对含有氧化铈的富镁涂 层进行拟合, 发现涂层浸泡 1-48 h 可采用等效电路 Model A 进行拟合, 浸泡 72-2400 h 可采用等效电路 Model B 进行拟合, 拟合结果亦示于图 4 中. 这表明, 加入氧化铈后并未改变富镁涂层对镁合金基体的 保护机制, 而是显著延长了保护时间.

图 8 为两种富镁涂层交流阻抗拟合参数 $Q_{\mathrm{v}} 、 R_{\mathrm{c}}$ 、 $Q_{\mathrm{d}} 、 R_{\mathrm{ct}}$ 随浸泡时间的变化曲线. 涂层电容的大小反 映了涂层对电解质溶液渗透的敏感性, 是评价涂层 性能的重要指标之一. 涂层电容 $Q_{\mathrm{c}}=\varepsilon \varepsilon_{0} A / d$, 其中, $A$ 、

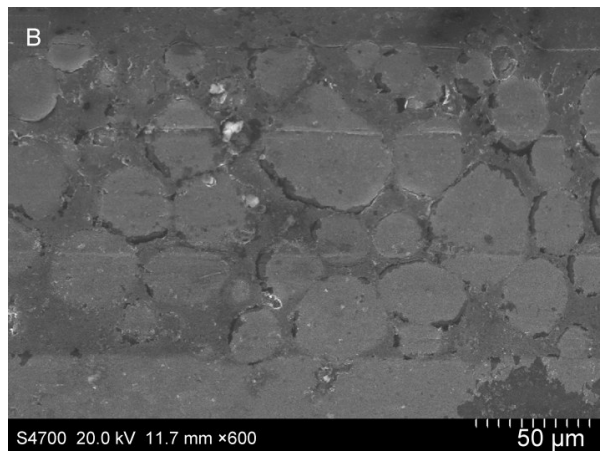



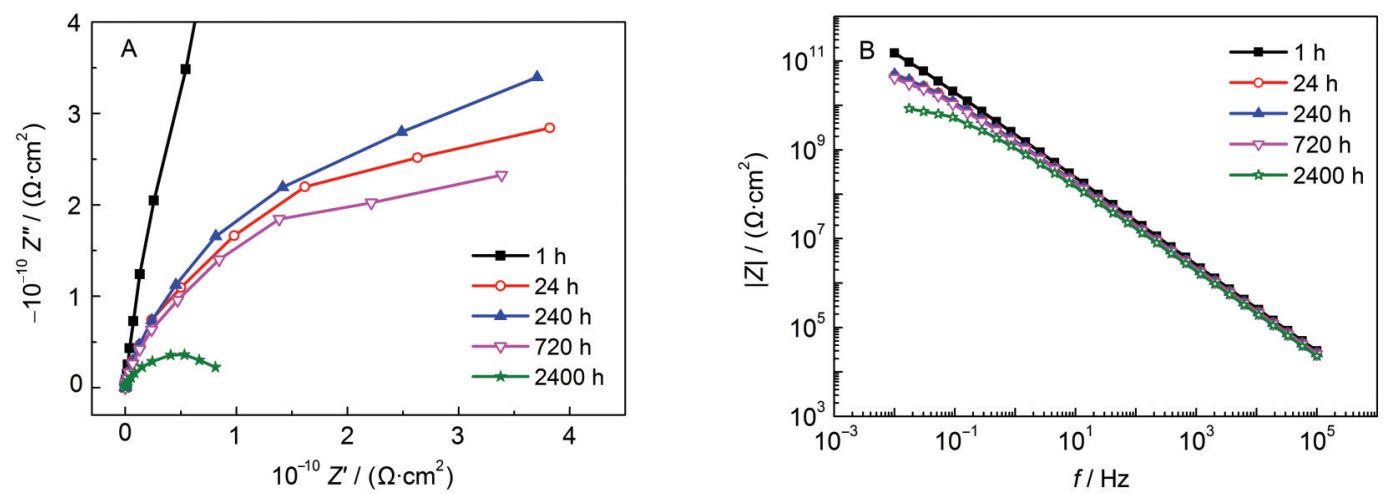

图 6 含有 $0.5 \%$ 氧化铈的富镁涂层在 $3 \%$ 氯化钠溶液中的交流阻抗谱图

Fig.6 EIS spectra of Mg-rich primer with $0.5 \%$ ceria in $3 \% \mathrm{NaCl}$ solution

(A) Nyquist plots; (B) Bode plots

$d$ 分别为涂层面积和厚度, $\varepsilon_{0}$ 是真空相对介电常数, $\varepsilon$ 为涂层相对介电常数. 水的介电常数远大于涂层的 介电常数, 因此电解质溶液向涂层渗透, 引起涂层 介电常数变化, 进而涂层电容发生变化. 图 8 显示, 浸泡初期, 两种涂层的电容值均迅速增大, 说明电 解质在浸泡初期迅速通过涂层孔隙进入涂层内部, 之后涂层电容一直处于稳定状态, 溶液渗透到涂层 中达到了饱和. 涂层中添加氧化铈后, 涂层电容值 明显降低, 这应归因于涂层中的粒子增多, 导致电 解质溶液到达基底的传输通道延长, 使涂层屏蔽性 能增强.

涂层中的微孔隙是电解质传输通道, Pettimen ${ }^{16}$ 和 Celis ${ }^{17}$ 等证明涂层孔隙率反映涂层体系耐蚀性能 的水平, 低孔隙率涂层具有较好的保护作用. EIS 法 是测量涂层微孔隙率的主要方法, ${ }^{18}$ 可以用涂层电 阻 $R_{\mathrm{c}}$ 表征涂层中微孔数量: $R_{\mathrm{c}}=l /\left(\kappa N A_{\mathrm{c}}\right){ }^{12}$ 其中, $l$ 为 介质传输通道长度, 一般为涂层膜厚, $\kappa$ 为电解质溶 液电导率, $N$ 为介质传输通道数目, $A_{\mathrm{c}}$ 表示传输通道

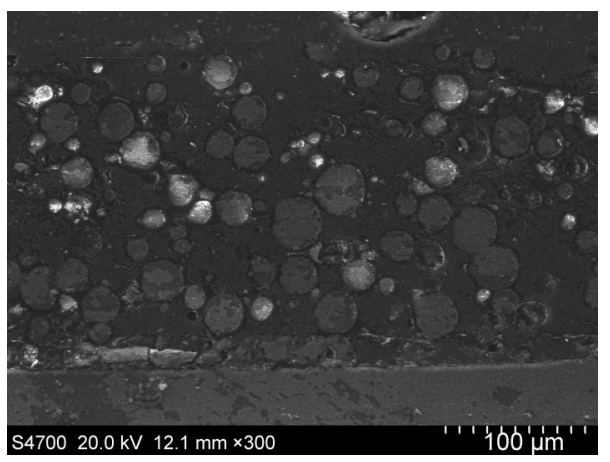

图 7 含有 $0.5 \%$ 氧化铈的富镁涂层在 $3 \%$ 氯化钠溶液中 浸泡 $2400 \mathrm{~h}$ 后涂层断面扫描形貌

Fig.7 Cross-section morphologies of the Mg-rich primer with $0.5 \%$ ceria after $2400 \mathrm{~h}$ immersion in $3 \% \mathrm{NaCl}$ solution
的平均截面面积. 涂层中添加氧化铈颗粒后, $R_{\mathrm{c}}$ 值增 大, 表明涂层中微孔数量减少, 涂层阻挡电解质溶 液渗透的能力提高. 前人 ${ }^{19,20}$ 研究也表明, 在金属表 面的膜层如硅烷膜中添加氧化铈纳米粒子, 能增加 涂层屏蔽性, 降低孔隙率, 进而增强涂层耐蚀性.

镁粉表面的界面双电层电容 $Q_{\mathrm{d} 1}$ 可提供镁粉电
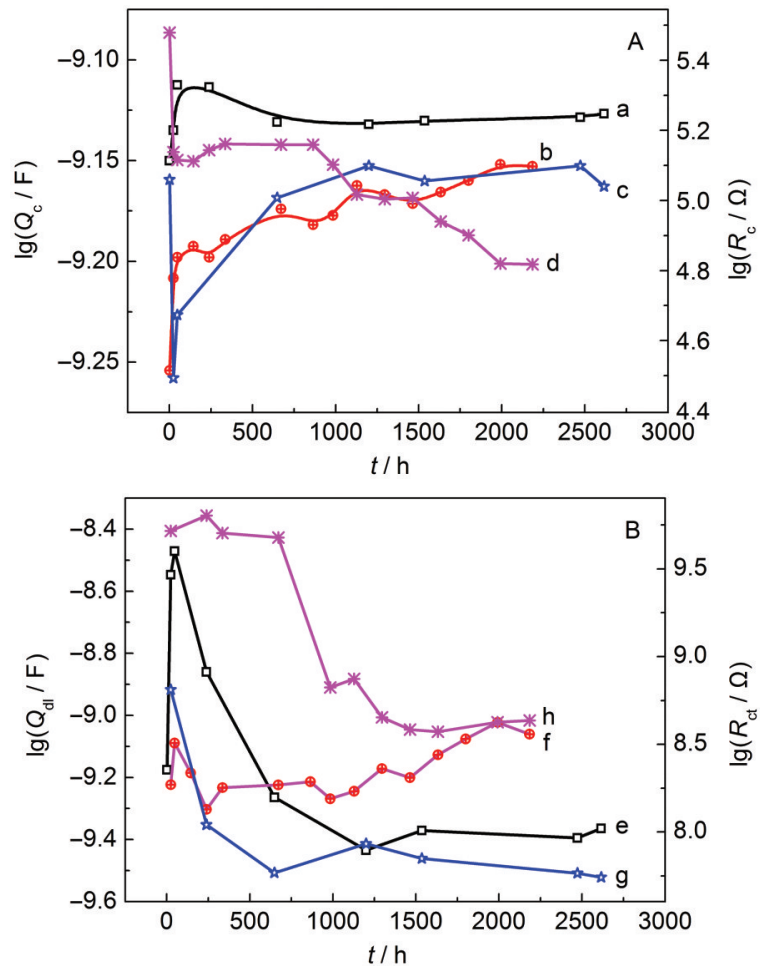

图 8 两种富镁涂层交流阻抗拟合参数随浸泡时间 的变化曲线

Fig.8 Variations of the obtained impedance parameters with time for the two Mg-rich primers with or without $0.5 \%$ ceria

(a) $50 \% \mathrm{Mg}, Q_{c}$; (b) $50 \% \mathrm{Mg}+0.5 \%$ ceria, $Q_{c}$; (c) $50 \% \mathrm{Mg}, R_{\mathrm{c}}$; (d) $50 \% \mathrm{Mg}+0.5 \%$ ceria, $R_{\mathrm{c}}$; (e) $50 \% \mathrm{Mg}, Q_{\mathrm{dl}}$; (f) $50 \% \mathrm{Mg}+0.5 \%$ ceria, $Q_{\mathrm{d}} ;$ (g) $50 \% \mathrm{Mg}, R_{\mathrm{ct}} ;$ (h) $50 \% \mathrm{Mg}+0.5 \%$ ceria, $R_{\mathrm{ct}}$ 
化学反应活性面积的信息. 不含氧化铈的涂层浸泡 初期 $Q_{\mathrm{d} 1}$ 值迅速升高, 说明电解质渗透到涂层, 与镁 粉接触, 快速和镁粉反应. 之后 $Q_{\mathrm{d} 1}$ 值迅速下降, 500 $\mathrm{h}$ 后基本稳定在一个较低值, 表明镁粉表面反应生 成的腐蚀产物阻挡了镁粉与电解质溶液接触, 使镁 粉活性降低. 浸泡初期含有氧化铈的富镁涂层 $Q_{\mathrm{d} 1}$ 值 比不含有氧化铈的富镁涂层 $Q_{\mathrm{d} 1}$ 值低, 一方面由于涂 层屏蔽性能增强, 电解质溶液不易渗透涂层, 另一 方面氧化铈的存在能抑制美粉反应活性, 使活性反 应面积减小. 随着浸泡时间延长, $Q_{\mathrm{d} 1}$ 值略有上升, 这 是由于随着电解质溶液渗透涂层, 镁粉表面的反应 活性面积增大.

界面反应电阻 $R_{\mathrm{ct}}$ 表征镁粉表面的腐蚀速率, $R_{\mathrm{ct}}$ 值越大, 则腐蚀越难进行, 腐蚀速率越小. ${ }^{21}$ 浸泡初 期, 不含有氧化铈的富镁涂层 $R_{\mathrm{ct}}$ 值迅速下降, 表明 镁粉迅速与电解质溶液反应, $500 \mathrm{~h}$ 后基本稳定在一 个较低值, 与 $Q_{\mathrm{dl}}$ 值反映的信息一致. 含有氧化铈的 富镁涂层 $R_{\mathrm{ct}}$ 值明显高于不含氧化铈的涂层, 且前 $700 \mathrm{~h}$ 处于稳定的较高值, 说明氧化铈的存在使镁粉 反应速率降低. $700 \mathrm{~h}$ 后 $R_{\mathrm{ct}}$ 值下降, 然后趋于稳定, 但仍明显高于不含氧化铈的涂层 $R_{\mathrm{ct}}$ 值.

由 $Q_{\mathrm{dl}}$ 和 $R_{\mathrm{ct}}$ 反应出来的信息可以看出, 氧化铈的 存在使镁粉的反应活性降低, 特别是氧化铈抑制镁 粉的反应活性, 延长镁粉的反应时间, 进而延长阴 极保护作用的时间.

\section{3 极化曲线测试}

将氧化铈在去离子水中制成浓度为 $250 \mathrm{mg} \cdot \mathrm{L}^{-1}$ 的悬浮液, 摚拌 $1 \mathrm{~h}$, 镁合金在悬浮液中浸泡 $30 \mathrm{~min}$, 然后在室温下在 $0.1 \%$ 的氯化钠溶液中进行极化曲 线测试, 图 9 为未经处理的镁合金试样和经过处理 的镁合金试样在 $0.1 \%$ 氯化钠溶液中的极化曲线.

测试中发现, 极化过程中, 未处理的试样表面 有大量气泡冒出, 测试完成后, 试样表面可看到许 多蚀点; 而经过处理的试样气泡生成速率明显降 低, 蚀点数量较少. 由图 9 看出, 镁合金试样在氧化 铈悬浮液中处理后, 腐蚀电位提高了约 $0.1 \mathrm{~V}$ (相对 于饱和甘录电极, $S C E),{ }^{22}$ 有文献 ${ }^{23}$ 认为, 氧化铈本身 是一种氧化剂, 可使腐蚀电位正移. Zhong 等 ${ }^{24}$ 报道, 在 AZ91D镁合金表面通过溶胶-凝胶法形成一层氧 化铈薄膜后, 与原合金相比, 在 $3.5 \%$ 氯化钠溶液中 腐蚀电流降低两个数量级, 腐蚀电位正移 $182 \mathrm{mV}$ (SCE), 并形成约 $100 \mathrm{mV}$ (SCE) 的针化区间, 表明在 $\mathrm{Cl}^{-}$溶液体系中, 氧化铈能显著保护镁合金, 提高耐

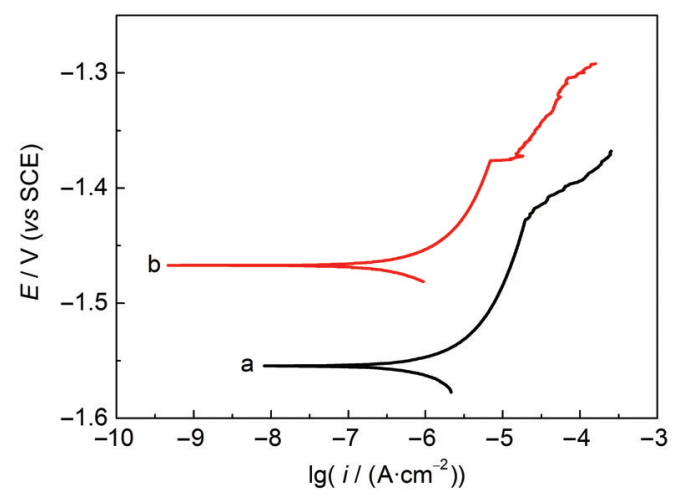

图9镁合金试样在 $0.1 \%$ 氯化钠溶液中的动电位 扫描极化曲线

Fig.9 Potentiodynamic polarization curves of AZ91D samples obtained in $0.1 \% \mathrm{NaCl}$ solution

(a) untreated AZ91D sample; (b) AZ91D sample treated in ceria suspension solution for $30 \mathrm{~min}$

蚀性. 本实验结果与文献 ${ }^{23,24}$ 所述一致.

关于氧化铈的作用机理在不同的文献中均有 报道. 在含有纳米氧化铈的氯化钠溶液中, 对纯锌 电极进行电化学测试, 显示纳米氧化铈颗粒表面的 zeta 电位较高, 说明带电粒子相互排斥, 能稳定覆盖 于金属表面, 防止聚集. ${ }^{13}$ 另有文献 ${ }^{25}$ 报道, 氧化铈比 氧对金属表面更具有亲和力, 降低了金属表面的氧 含量, 进而降低腐蚀速率. 因此, 可以认为纳米氧化 铈在富镁涂层中的作用机理是: 氧化铈比氧更具亲 和性, 容易聚集并稳定覆盖于纯镁颗粒表面, 降低 纯镁的电化学反应活性, 使镁粉对 AZ91D基体的保 护效果延长. 另一方面, 氧化铈在 AZ91D 合金表面 覆盖, 能够使基体电位提高, 腐蚀速率降低, 同时也 有利于富镁涂层对基体的阴极保护作用. 此外, 纳 米氧化铈颗粒在涂层中也能够一定程度增强涂层 的屏蔽性能.

\section{4 结 论}

(1) 在富镁涂层中添加氧化铈颗粒, 通过 Machu 测试发现, 添加量较少 $(0.1 \%)$ 时, 对涂层耐蚀性无影 响; 添加量过多(3\%)时, 涂层耐蚀性降低. 添加氧化 铈颗粒为 $0.5 \%$ 时, 涂层的阻抗升高, 对 AZ91D镁合 金基体的保护性能明显提高.

(2) 添加氧化铈不改变富镁涂层对 AZ91D镁合 金的保护机制, 而是明显延长涂层的服役寿命; 氧 化铈能够降低纯镁颗粒的电化学反应活性, 使镁粉 腐蚀速率降低, 阴极保护时间延长; 添加一定量氧 化铈后, 也有利于涂层屏蔽性能提高. 
(3) 氧化铈能降低AZ91D镁合金表面阳极腐蚀 电流密度, 提高镁合金腐蚀电位, 从而有利于富镁 涂层发挥阴极保护作用.

\section{References}

(1) Mordike, B. L.; Ebert, T. Mater. Sci. Eng. A 2001, 302, 37.

(2) Gray, J. E.; Luan, B. J. Alloy. Compd. 2002, 336, 88.

(3) Bierwagen, G. P. Prog. Org. Coat. 1996, 28, 43.

(4) Zhang, J. Q.; Mansfeld, F. Corros. Sci. Prot. Technol. 1989, 1, 15. [张鉴清, Mansfeld, F. 腐蚀科学与防护技术, 1989, 1, 15.]

(5) Zhang, J. T. Electrochemical Investigation on Water Transport Behavior of Organic Coating and Degradation Mechanism of Coated-Metals. Ph. D. Dissertation, Zhejing University, Hangzhou, 2005. [张金涛. 有机涂层中水传输与涂层金属失 效机制的电化学研究[D]. 杭州: 浙江大学, 2005.]

(6) Marchebois, H.; Joiret, S.; Savall, C.; Bernard, J.; Touzain, S. Surf. Coat. Technol. 2002, 157, 151.

(7) Marchebois, H.; Savall, C.; Bernard, J.; Touzain, S. Electrochim. Acta 2004, 49, 2945.

(8) Bierwagen, G.; Brown, R.; Battocchi, D.; Hayes, S. Prog. Org. Coat. 2010, 67, 195.

(9) Battocchi, D.; Simões, A. M.; Tallman, D. E.; Bierwagen, G. P. Corrosion Sci. 2006, 48, 1292.

(10) Simões, A. M.; Battocchi, D.; Tallman, D. E.; Bierwagen, G. P. Corrosion Sci. 2007, 49, 3838.

(11) Yu, B. L.; Uan, J. Y. Scripta Materialia 2006, 54, 1253.

(12) Lu, X. Y.; Zuo, Y.; Zhao, X. H.; Tang, Y. M.; Feng, X. G. Corrosion Sci. 2011, 53, 153.

(13) Montemor, M. F.; Pinto, R.; Ferreira, M. G. S. Electrochim.
Acta 2009, 54, 5179.

(14) Schem, M.; Schmidt, T.; Gerwann, J.; Wittmar, M.; Veith, M.; Thompson, G. E.; Molchan, I. S.; Hashimoto, T.; Skeldon, P.; Phani, A. R.; Santucci, S.; Zheludkevich, M. L. Corrosion Sci. 2009, 51, 2304.

(15) Hu, J. M.; Zhang, J. Q.; Xie, D. M.; Cao, C. N. Acta Phys. Chim. Sin. 2003, 19, 144. [胡吉明, 张鉴清, 谢德明, 曹楚南. 物理化学学报, 2003, 19, 144.]

(16) Penttinen, I. M.; Korhonen, A. S.; Harju, E.; Turkia, M. A.; Forsén, O.; Ristolainen, E. O. Surf. Coat. Technol. 1992, 50, 161.

(17) Celis, J. P.; Drees, D.; Maesen, E.; Roos, J. R. Thin Solid Films 1993, 224, 58.

(18) Notter, I. M.; Gabe, D. R. Corrosion Sci. 1993, 34, 851.

(19) Montemor, M. F.; Ferreira, M. G. S. Prog. Org. Coat. 2008, 63, 330.

(20) Montemor, M. F.; Ferreira, M. G. S. Electrochim. Acta 2007, 52, 6976.

(21) Yu, H. C.; Chen, B. Z.; Shi, X. C.; Li, B.; Wu, H. Y. Acta Phys. Chim. Sin. 2008, 24, 1465. [余会成, 陈白珍, 石西昌, 李 兵, 吴海鹰. 物理化学学报, 2008, 24, 1465.]

(22) Li, L. J.; Yao, Z. M.; Lei, J. L.; Xu, H.; Zhang, S. T.; Pan, F. S. Acta Phys. -Chim. Sin. 2009, 25, 1332. [李凌杰, 姚志明, 雷惊 雷, 徐 辉, 张胜涛, 潘复生. 物理化学学报, 2009, 25, 1332.]

(23) Alves, V. A.; da Silva, L. A.; Boodts, J. F. C. Electrochim. Acta 1998, 44, 1525.

(24) Zhong, X. K.; Li, Q.; Hu, J. Y.; Lu, Y. H. Corrosion Sci. 2008, $50,2304$.

(25) Nickolova, D.; Stoyanova, E.; Stoychev, D.; Avramova, I.; Stefanov, P. Surf. Coat. Technol. 2008, 202, 1876. 